\title{
EFFECT OF OXYGENATED HYDROCARBON ADDITIVES ON EXHAUST EMISSIONS OF A DIESEL ENGINE
}

\author{
C. Sundar Raj ${ }^{1}$ and S. Sendilvelan ${ }^{2}$ \\ ${ }^{1}$ Imayam College of Engineering,Kannanur, Thuraiyur, Trichy \& Dr. MGR Educational \\ and Research Institute, Chennai, India. Phone: +91-9443651442 \\ ${ }^{2}$ Aksheyaa college of engineering, Puludivakkam, madhurantagam taluk, \\ Kancheepuram district - 603 314. India.Tel. +91-9381010709. Fax: +91- 44 - 22293345 \\ E-mail: csundarraj@yahoo.com,chockalingamsundarraj@gmail.com
}

\begin{abstract}
The use of oxygenated fuels seems to be a promising solution for reducing particulate emissions in existing and future diesel motor vehicles. In this work, the influence of the addition of oxygenated hydrocarbons to diesel fuels on performance and emission parameters of a diesel engine is experimentally studied. 3-Pentanone $\left(\mathrm{C}_{5} \mathrm{H}_{10} \mathrm{O}\right)$ and Methyl anon $\left(\mathrm{C}_{7} \mathrm{H}_{12} \mathrm{O}\right)$ were used as oxygenated fuel additives. It was found that the addition of oxygenated hydrocarbons reduced the production of soot precursors with respect to the availability of oxygen content in the fuel. On the other hand, a serious increase of NOx emissions is observed. For this reason the use of exhaust gas recirculation (EGR) to control NOx emissions is examined. From the analysis of it is examined experimental findings, it is seen that the use of EGR causes a sharp reduction in NOx and smoke simultaneously. On the other hand, EGR results in a slight reduction of engine efficiency and maximum combustion pressure which in any case does not alter the benefits obtained from the oxygenated fuel.
\end{abstract}

Key words: Oxygenated fuel, Exhaust gas recirculation, Performance and emission parameters

\section{INTRODUCTION}

Diesel engines have the advantages of high thermal efficiency and lower emission of $\mathrm{CO}$ and $\mathrm{HC}$. However, they have the disadvantage of producing smoke, particulate matter and oxides of nitrogen, and it is difficult to reduce both NOx, and smoke density simultaneously in a diesel engine due to the trade off between NOx and smoke. A substantial amount of effort has been directed at providing solutions to these problems. The addition of oxygen containing compounds to diesel fuel has been proposed as a method to complete the oxidation of the carbonaceous particulate matter and associated hydrocarbons. In addition, many oxygenates have high cetane number and their association with diesel results in a high cetane number and hence lower exhaust emissions. Due to these advantages, there is a growing interest in the introduction of oxygenates into diesel fuel. Low molecular weight alcohols such as ethanol and t-butyl alcohol have been reported to reduce emissions (Ecklund et al., 1984). However, both the low flash points and high water partitioning of these alcohols make them unacceptable. Di methyl ether (DME) was considered as an ignition-improving additive for methanol powered diesel engines (Brook et al., 1984; Sorenson and Mikkelsen, 1995). However, DME is a gaseous fuel and therefore requires that a vehicle be adapted 
for gaseous operation. In addition, the fuel delivery infrastructure is not currently suitable to distribute large quantities of a gaseous fuel. For these reasons, there is interest in new liquid compression ignition fuels or fuel additives, which have high cetane rating and reduce particulate emissions and at the same time they are compatible with current vehicle technology and fuel delivery infrastructure. Carbonates, including dimethyl carbonate, diethyl carbonate, and dimethyl dicarbonate, have been successfully demonstrated to reduce particulate (West et al., 1990). Dimethyl carbonate suffers from having a low flash point. Diglyme is one oxygenate that has been included in several studies. While diglyme has acceptable fuel blending properties, its high cost makes its use prohibitive. Other oxygenates that have been investigated include various ethers, glycol ether acetates, and ketones (Bennethum and Winsor, 1991).

Bailey et al. (1997) suggested di ethyl ether (DEE) as a potential replacement fuel for CI Engines. The molecular weights of DEE are low; the molecules have high hydrogen to carbon ratios and a low number of carbon-to-carbon bonds. All these properties lower the tendency to form solid carbon particulates during combustion. The molecules contain oxygen, which also suppress the formation of soot. The molecular bonds break up to radicals at reasonable activation energy, which leads to high cetane numbers. DEE has long been known as a cold start aid for engines, is an oxygenated renewable fuel, which is completely miscible with diesel. Mohanan et al. (2003) studied the effect of DEE on the performance and emissions of a four-stroke direct injection diesel engine and found that 5\% DEE can be blended with diesel fuel to improve the performance and to reduce emissions of the diesel engine even though experiments were carried out successfully up to $25 \%$ DEE blend. Yanfeng et al. (2007) proved $15 \%$ of 2methoxyethyl acetate (MEA) can be used to decrease exhaust smoke as a new oxygenated additive of diesel with marginal increase in efficiency

Raj et al. (2009a) investigated the effect of ethanol diesel blends and reported $30 \%$ ethanol with $60 \%$ diesel along with a new oxygenate 1,4 dioxane increase the efficiency by $6 \%$ and reduce smoke density with a penalty in NOx emissions. Raj et al. (2009b) also found that $10 \%$ addition of dioxane alone as an oxygenated additive is capable of increasing the efficiency by $2 \%$ and reduces smoke density with marginal increase in NOx emissions. The literature review clearly indicates that the presence of oxygen molecules in the fuel influences complete combustion and hence increases the efficiency, but there is a trade off between NOx and smoke.

The effects of EGR on diesel combustion were visually examined in a singlecylinder, heavy-duty research engine by Husberg et al. (2004) and NOx emissions were reduced from over $500 \mathrm{ppm}$ at $0 \%$ EGR to $5 \mathrm{ppm}$ at 55\% EGR, and higher levels of EGR (approximately 35\% or more) reduce efficiency. Kouremenos et al. (2001) showed in an experimental and theoretical study that the use of EGR causes a sharp reduction of NOx and an increase of soot emissions. Dederichs et al. (2002) outlined the main technical issues of EGR technology for thermal barrier coated HD engines with EGR up to $30 \%$ and more of the exhaust gases and found the same results. Dürnholz et al. (1992) reported in particular that so called 'hot EGR', which keeps the temperature of the re circulated exhaust gases at a very high level, not only helps reduce NOx but also contributes distinctly to achieving lower hydrocarbon (HC) and PM emissions. In addition, there is no adverse affect of EGR on the fuel economy. The findings from smoke point measurements and high-pressure combustion tests that oxygenates are effective soot suppressants in diesel combustion motivated studies on oxygenates and to find the solution for simultaneous reduction in smoke and NOx emissions without affecting the performance EGR. 
This paper aims to study the influence of two new oxygenates 3-Pentanone (PN) and Methyl anon (MN) which were not addressed earlier, having favorable properties such as low molecular weight and almost similar density to diesel, on exhaust emissions, including: oxides of nitrogen (NOx), hydro carbon (HC) and smoke density of a diesel engine with and without application of EGR.

\section{EXPERIMENTAL SETUP}

Experiments were conducted on a four stroke, twin cylinder, water cooled diesel engine (SIMPSONS, S 217) connected with a water cooled eddy current dynamometer (DYNASPEDE). The rated power of the engine was $19 \mathrm{~kW}$ at $1500 \mathrm{rpm}$. The engine was operated at a constant speed of $1500 \mathrm{rpm}$ and standard injection pressure of 200 bar. The fuel flow rate was measured on a volume basis using a burette and a stop watch. K-type thermocouple and a digital display were employed to note the exhaust gas temperature. A smoke meter (AVL 437C) was used for measuring smoke density. NOx emission was measured by a Di gas analyser (AVL 444). In cylinder pressure was measured with the help of a combustion analyser (AVL, 619 indimeter hardware, indwin software version 2.2). The schematic experimental setup is shown in Figure 1 and the experiments were conducted in two phases.

\section{Experimental Procedure}

Base data was generated with standard diesel fuel. Subsequently three fuel blends, namely 1\%, 3\% and 5\% (by volume) of Pentanone (PN) and Methyl anon (MN) (each) with diesel were prepared and tested. Readings were taken when the engine was operated at a constant speed of $1500 \mathrm{rpm}$ for all loads. Parameters such as engine speed, fuel flow and the emission characteristics of NOx and smoke were recorded. The performance of the engine was evaluated in terms of brake thermal efficiency, brake power, and specific fuel consumption from the above parameters. Combustion characteristics such as cylinder pressure and heat release rate were noted for different loading conditions using the combustion analyser. In the second phase, experiments were conducted on the engine with $25 \%$ EGR for the unaltered fuel and three different blends ranges from 1 to $5 \%$ of diesel by volume of two different additives viz.3Pentanone (PN) and Methyl anon (MN) and experimental results were analysed and compared. The volatility and flammability properties of the fuel components are listed in Table 1.

Table 1 Test fuel properties

\begin{tabular}{|c|c|c|c|c|c|c|}
\hline & 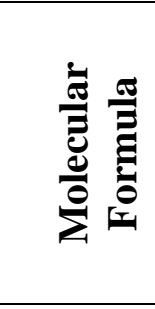 & 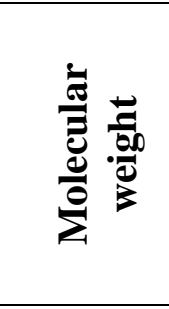 & 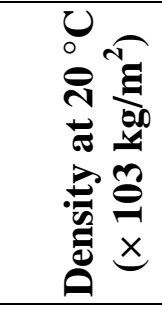 & 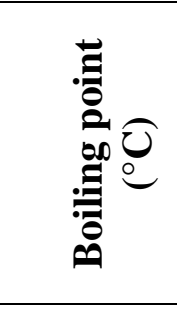 & $\begin{array}{l}0 \\
0 \\
0 \\
0 \\
0 \\
\frac{1}{0} \\
\frac{\pi}{2} \\
\frac{\pi}{2}\end{array}$ & 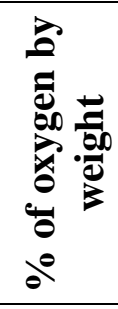 \\
\hline Diesel & CxHy & $190-220$ & 0.829 & $180-360$ & $65-88$ & 0 \\
\hline 3-Pentanon & $\mathrm{C}_{5} \mathrm{H}_{10} \mathrm{O}$ & 86.13 & 0.81 & $101-103$ & 7 & 18.57 \\
\hline Methyl anon & $\mathrm{C}_{7} \mathrm{H}_{12} \mathrm{O}$ & 112.2 & 0.858 & 120.1 & 63.6 & 14.26 \\
\hline
\end{tabular}




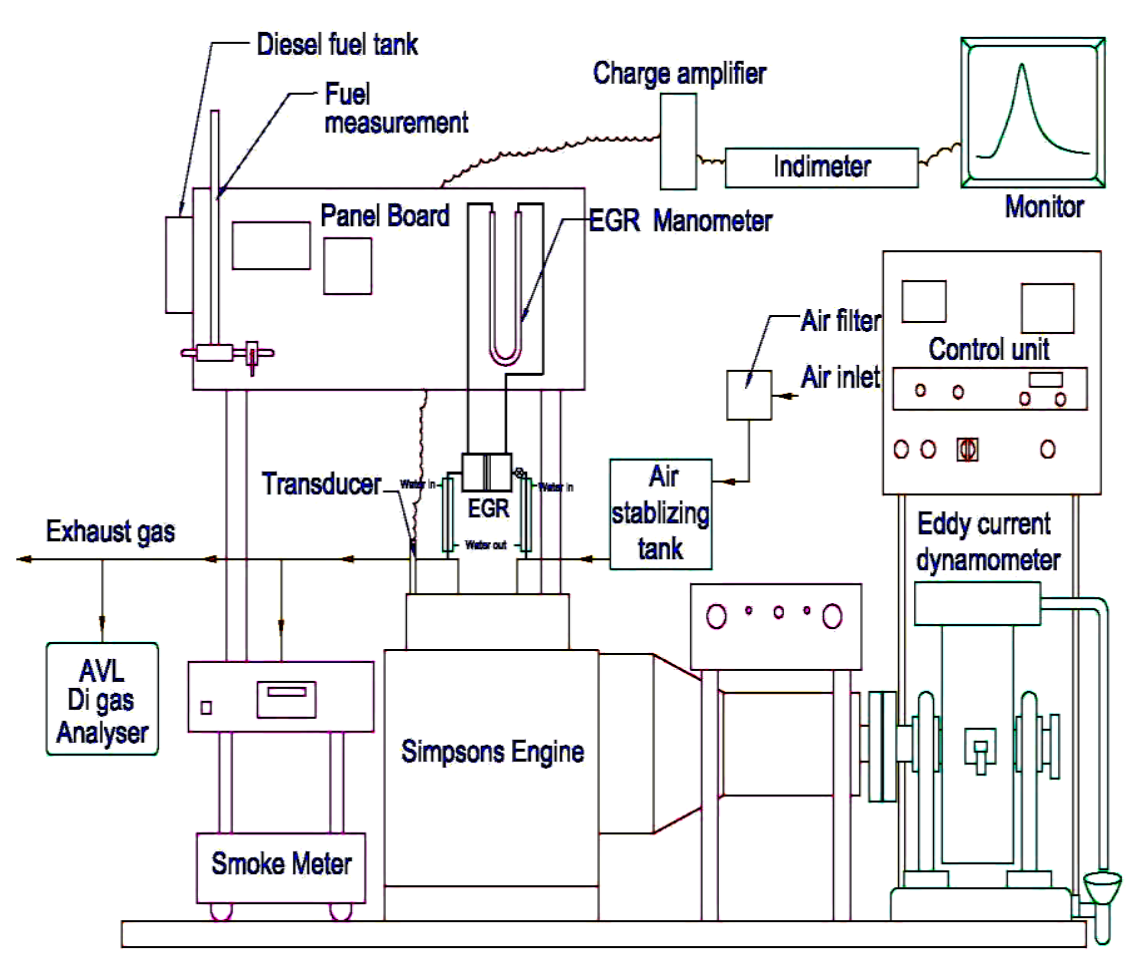

Figure 1. Experimental Setup

\section{RESULTS AND DISCUSSION}

The stoichiometric air requirement for the combustion of additives is lower, since they already contain oxygen in their structure, hence a larger amount of fuel can be burnt in a given amount of air and hence the BSFC decreases for the blends compared with baseline fuel (Raj et al., 2009a) as shown in Figure 2. From the figure it is observed that the addition of PN reduce the BSFC due to the availability of more oxygen. However, $\mathrm{MN}$, due to having less oxygen and a higher molecular weight compared with PN as indicated in Table 1, lowers the heat value of the mixture. As a result, BSFC will increase as the blended fuels with high MN concentration are used. Among the two additives, $1 \% \mathrm{MN}$ and 5\% PN show lower BSFC and higher brake thermal efficiency and hence they are treated as the optimum blends. The effect of $25 \%$ EGR on the optimum blend is illustrated in Figure 3. A slight increase in BSFC is observed for EGR as some of the intake air is replaced with hot exhaust gases as demonstated by Husberg et al. (2004).

The presence of oxygen, due to the additives in the oxygenated fuel, improves the combustion, especially diffusion combustion (Yanfeng et al., 2007) and hence increases the brake thermal efficiency. Figure 4 compares the effect of oxygenated fuel on the brake thermal efficiency for different blends of MN and PN. PN contain more oxygen than $\mathrm{MN}$ and this extra oxygen helps in oxidation of carbonaceous particulate matter and associated hydrocarbons, resulting in improved efficiency the for higher blends. The addition of MN results in lower brake thermal efficiency due to the decrease in the mixture's heat value. The maximum brake thermal efficiency occurs for $1 \% \mathrm{MN}$ and 5\% PN blends. 25\% EGR slightly reduces the brake thermal efficiency as the amount of fresh oxygen available for combustion gets decreased due to replacement by exhaust gas (Husberg et al., 2004). The effect of EGR on optimum blends is illustrated in Figure 5. 


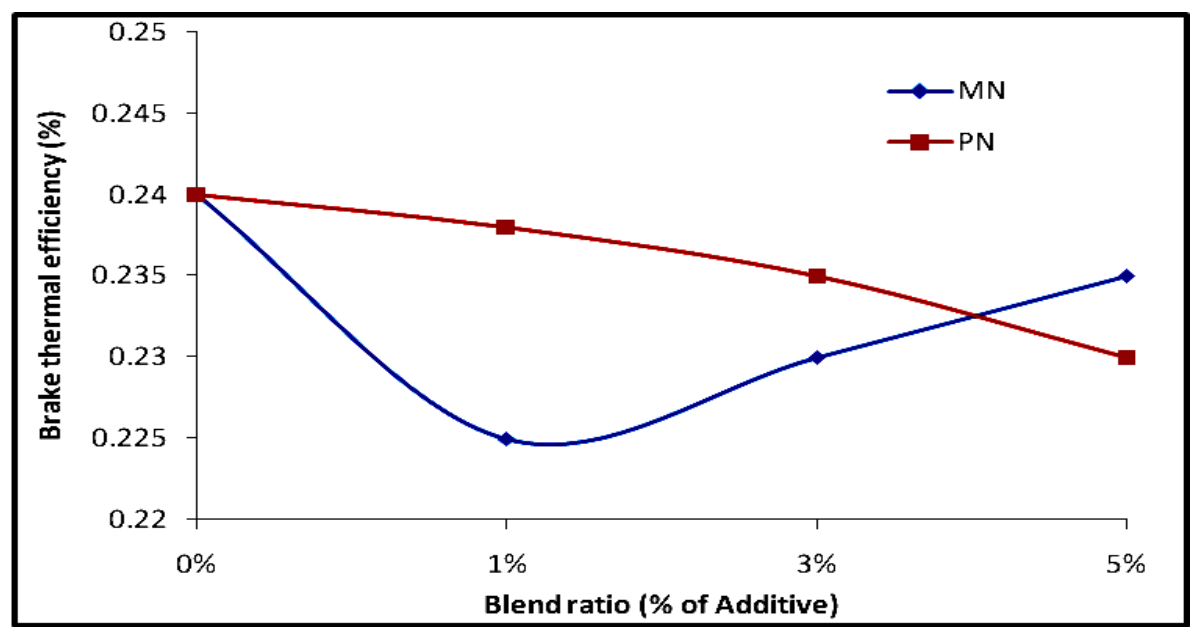

Figure 2. Variation in BSFC for oxygenated fuel at maximum load

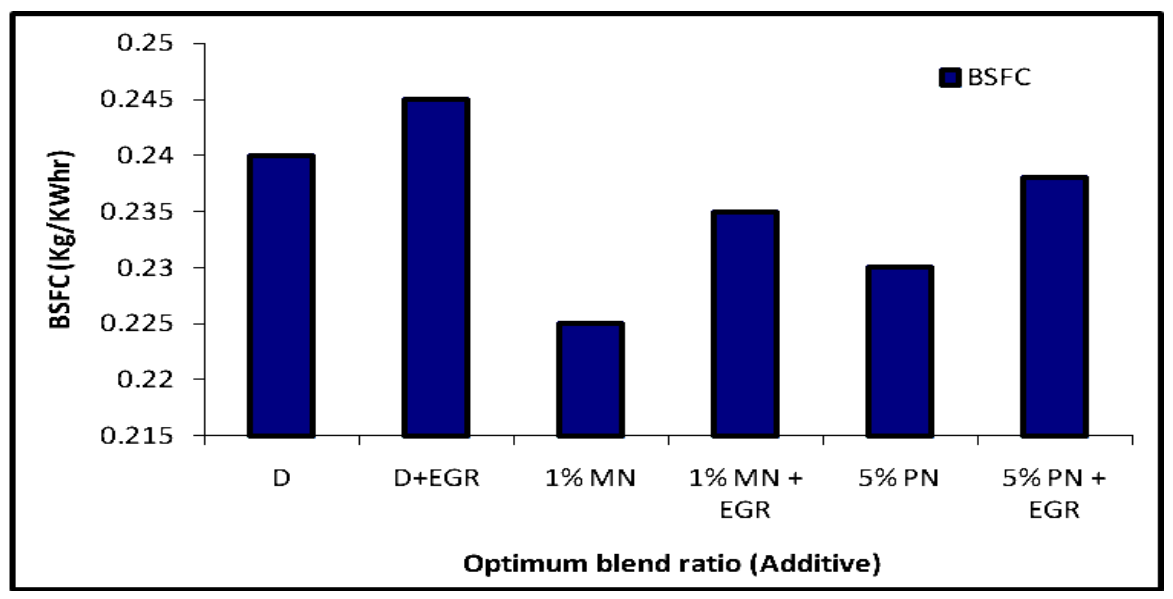

Figure 3. Effect of EGR on BSFC for optimum blends at maximum load

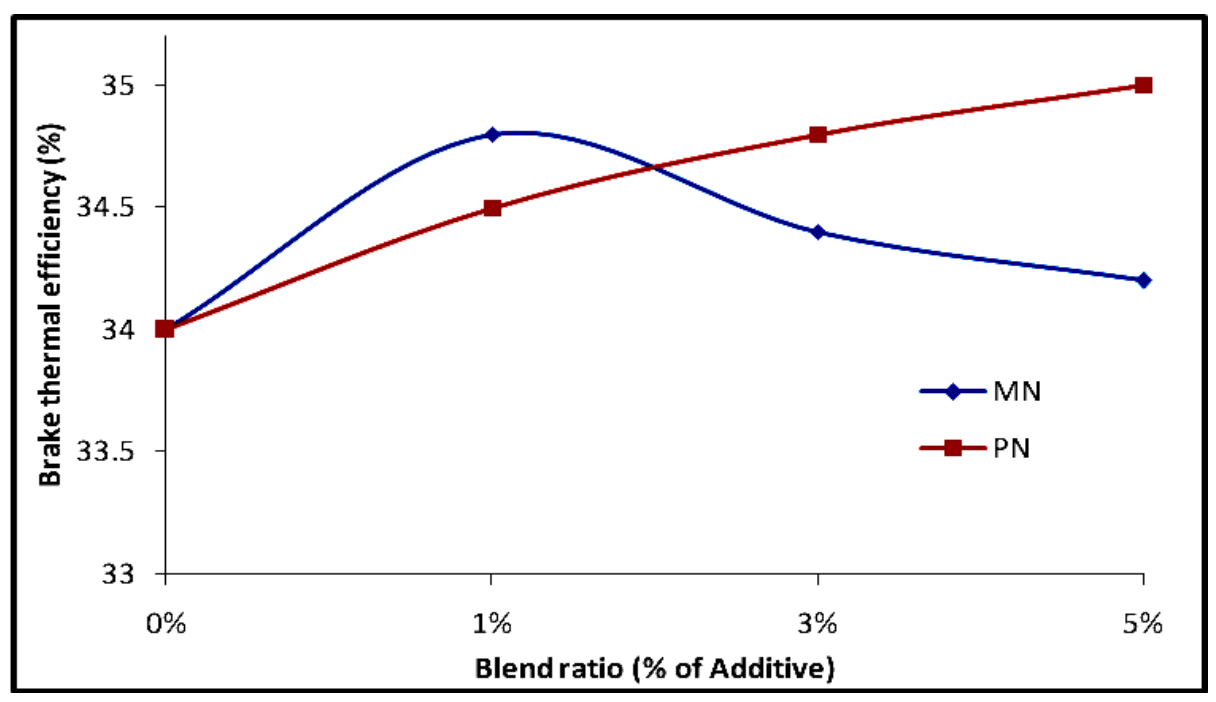

Figure 4. Vaiation in brake thermal efficiency for oxygenated fuel at maximum load 


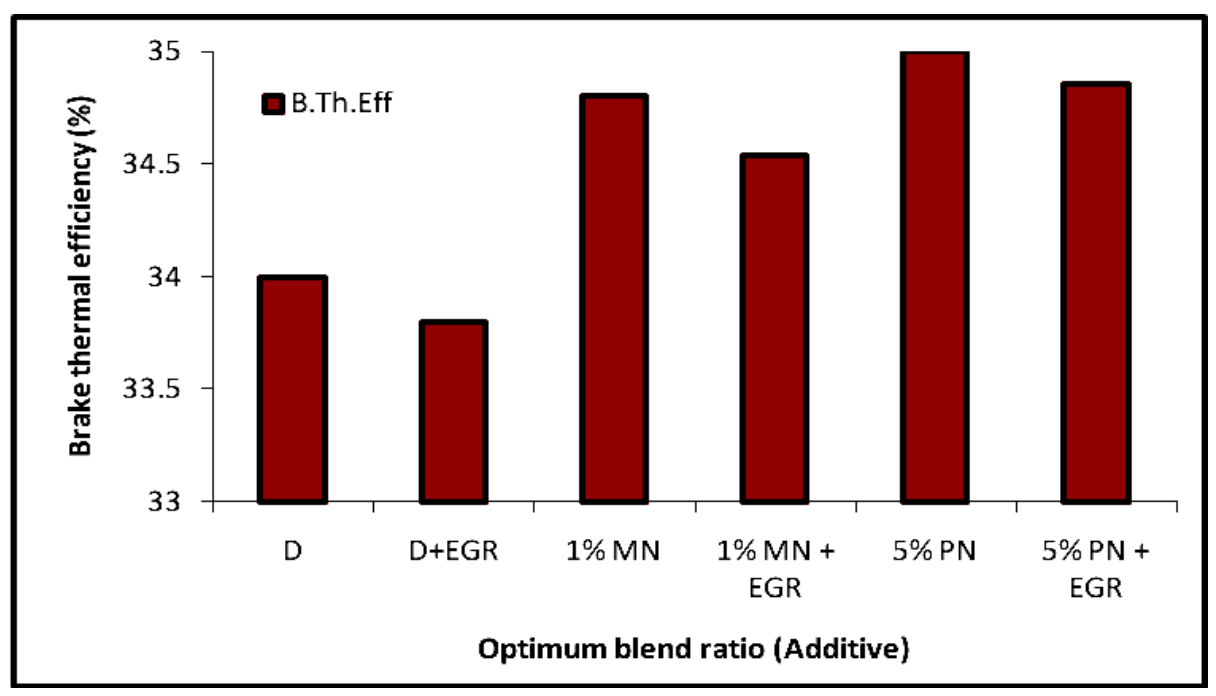

Figure 5. Effect of EGR on brake thermal efficiency for optimum blends at maximum load

The addition of oxygenates decreases the smoke density as shown in Figure 6 due to the increased heat release rate and more complete combustion of the oxygenated fuel by acting as an ignition improver (Mohanan et al., 2003). The variation in smoke density for different MN and PN blends at peak load is shown in Figure 6. A maximum of $15 \mathrm{HSU}$ reductions in smoke density for $1 \% \mathrm{MN}$ and $35 \mathrm{HSU}$ for $5 \% \mathrm{PN}$ blend ratios were observed at peak load. It is also observed that the smoke density reduction rate is high between part and maximum load. EGR increased the smoke density especially above $50 \%$ of loading conditions due to deterioration in diffusion combustion. (Kouremenos et al., 2001), and the anticipated increase in smoke density is apparent in Figure 7. It is further noticed a decrease in smoke density for oxygenated fuels at low loads as the effect of deterioration in diffusion combustion is low due to the presence of oxygen molecules.

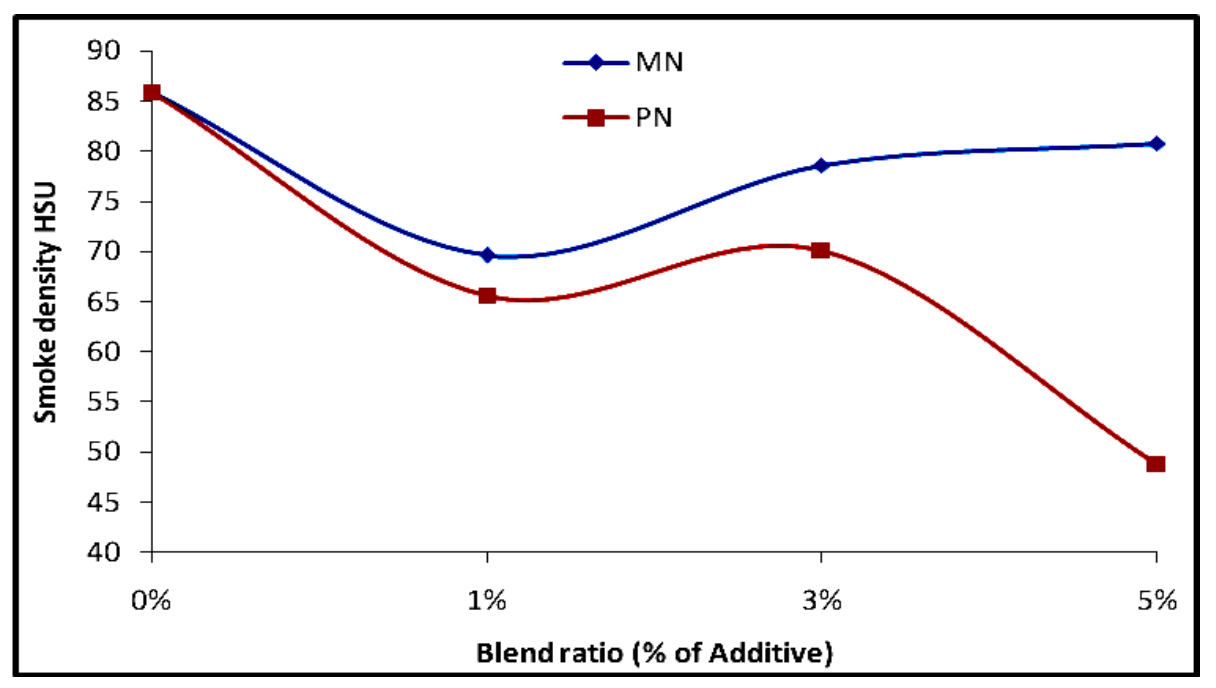

Figure 6. Variation in smoke density for oxygenated fuels at maximum load 


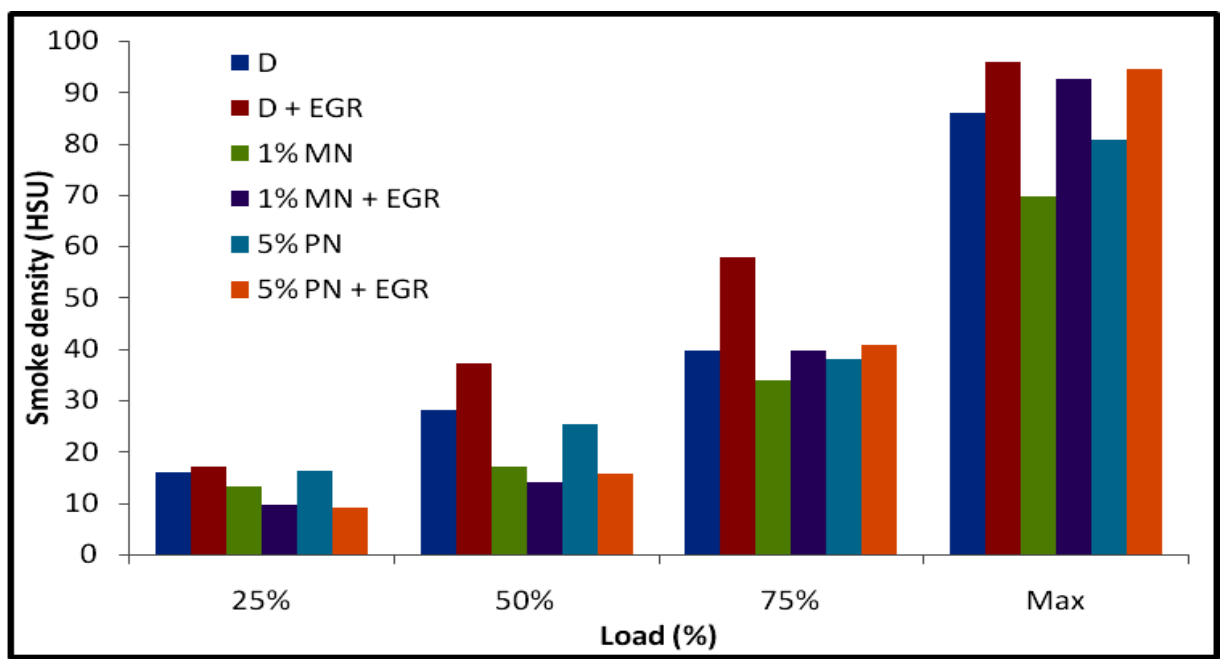

Figure 7. Effect of EGR on smoke density with load for optimum blend fuels

Figure 8 shows the variation in $\mathrm{HC}$ emissions for the unaltered fuel and the oxygenated fuels. Both the additives have the capacity to reduce $\mathrm{HC}$ emissions due to the complete combustion. The variation in the amount of reduction depends on the availability of the amount of oxygen irrespective of its chemical structure as illustrated by Bailey et al. (1997). The reductions of HC emissions are higher at low loads than at the maximum load. The influence of EGR on HC emission is shown in Figure 9. It is clear from the figure that EGR decreases HC emissions as illustrated by Dürnholz et al. (1992), but a slight increase was observed at maximum loading conditions due to the reduction in the availability of oxygen.

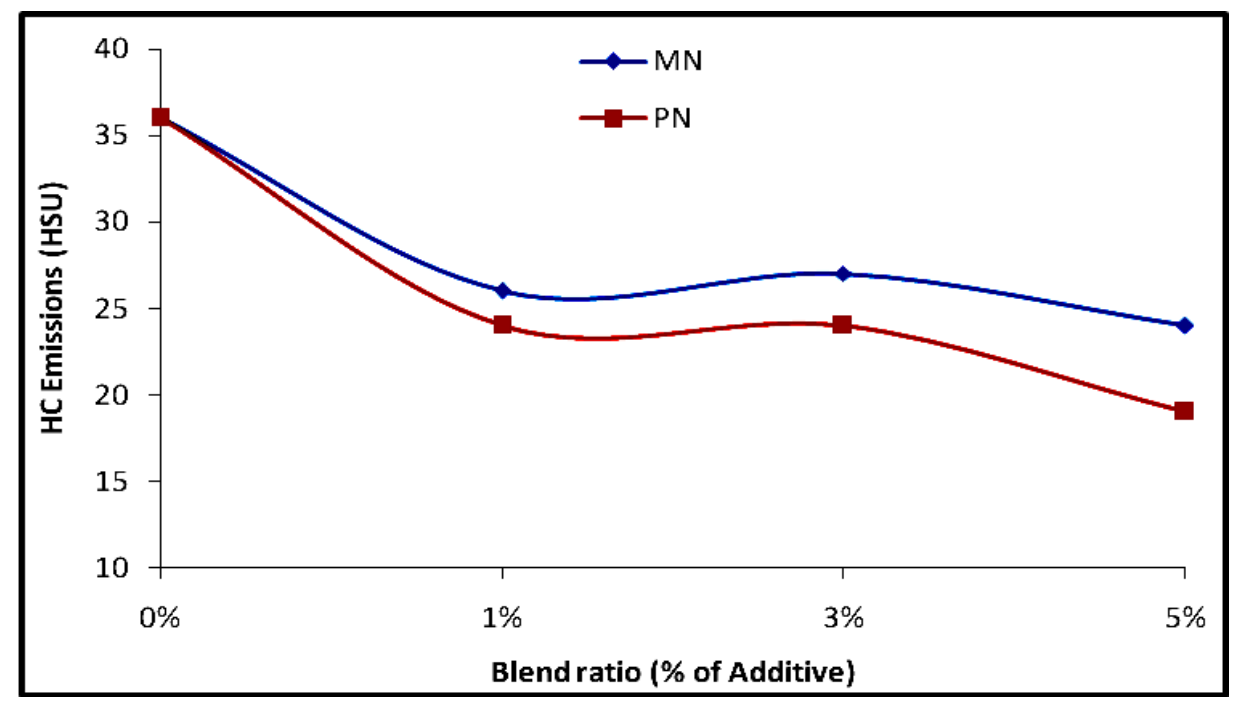

Figure 8. Variation in $\mathrm{HC}$ emissions for oxygenated fuels at maximum load 


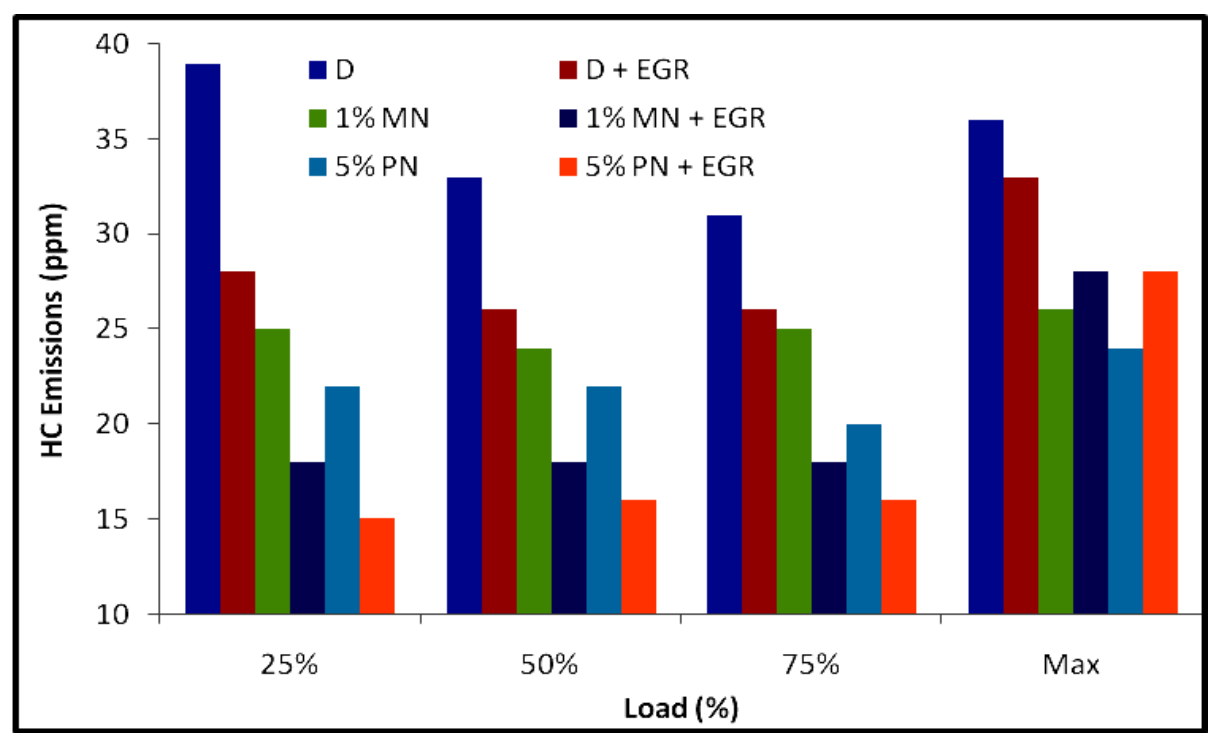

Figure 9. Effect of EGR on HC emissions with load for optimum blend fuels

Nitrogen oxides emissions are predominately temperature phenomena, the presence of oxygen increases the heat release rate for the oxygenated fuel and hence the NOx emission will be high. The anticipated increase in NOx emissions as a function of increasing additive concentration is apparent in Figure 10. It can be seen that NOx emissions of lower blends increase more rapidly than those of higher additive proportion at peak load. MN emits more NOx than PN. EGR is a useful technique for reducing NOx formation in the combustion chamber. The exhaust consists of $\mathrm{CO}_{2}, \mathrm{~N}_{2}$ and water vapours mainly. When a part of this exhaust gas is re-circulated to the cylinder, it acts as diluents to the combusting mixture. This also reduces the $\mathrm{O}_{2}$ concentration in the combustion chamber (Husberg et al., 2004). The specific heat of the EGR is much higher than fresh air; hence EGR increases the heat capacity (specific heat) of the intake charge, thus decreasing the temperature rise for the same heat release in the combustion chamber (Dederichs et al., 2002).

Figure 11 shows the variations in NOx emissions under various loading conditions for diesel and optimum blends with and without EGR and the anticipated reduction in NOx emission for EGR is apparent from the figure. The presence of oxygen molecules increases the spray optimization and evaporation. Hence it improves the combustion process of the engine. The noticeable reductions in BSFC, HC, Smoke emissions and increase in NOx emissions indicate that the addition of MN or PN improves combustion efficiency. 


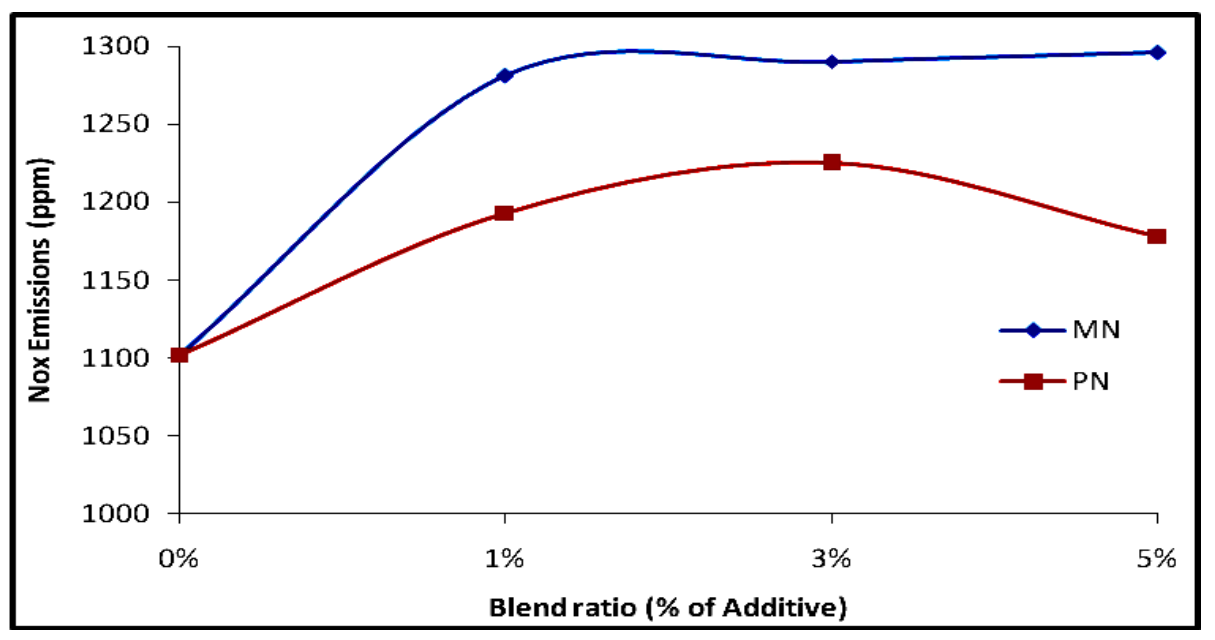

Figure 10. Variation in NOx emissions for oxygenated fuels at maximum load

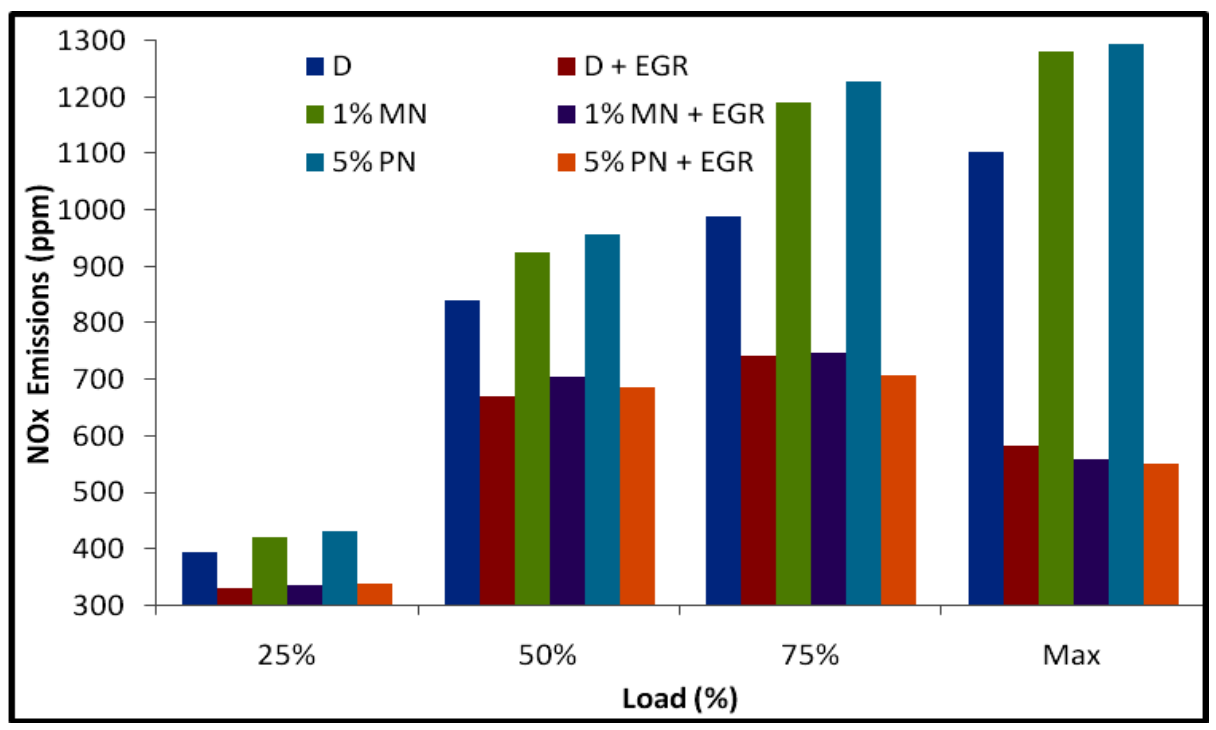

Figure 11. Effect of EGR on HC emissions with load for optimum blend fuels

Figure 12 illustrates the maximum inside cylinder pressure of diesel and oxygenated additive blended diesel fuels. It is found that at the same engine speed and maximum load, the cylinder pressure shows greater differences for unaltered fuel and oxygenated fuel. The peak pressure of unaltered fuel is 92 bar and is reduced to 88 bar by $1 \% \mathrm{MN}$ blends and 91 bar by $1 \% \mathrm{PN}$ blends, and the pressure increases with addition of additives. 


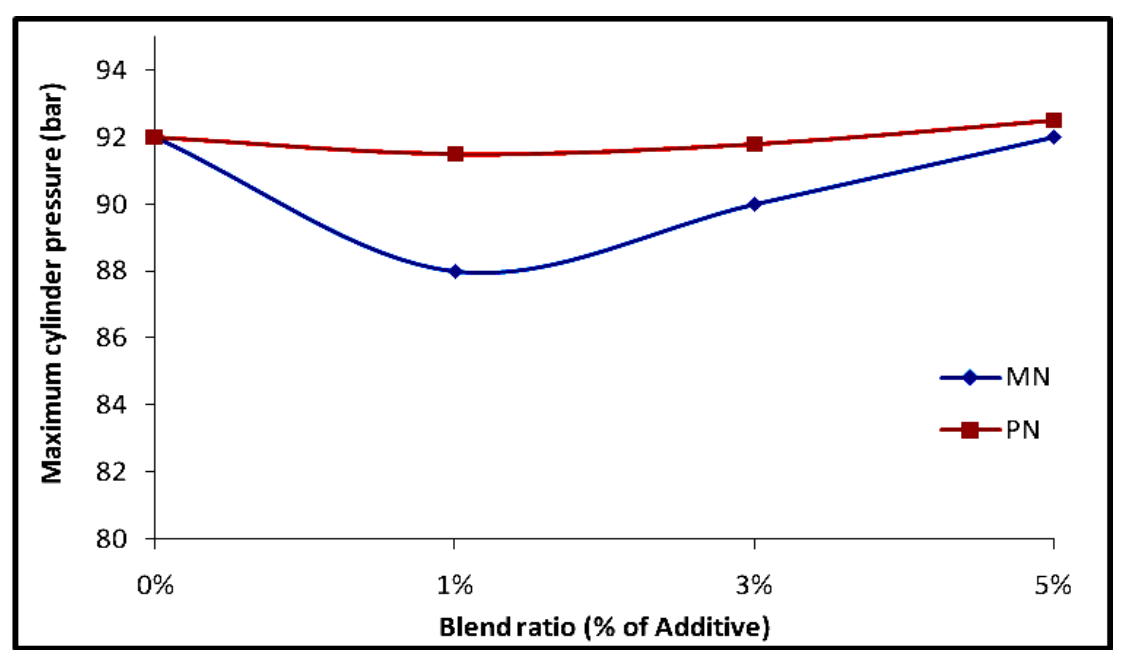

Figure 12. Variation in cylinder pressure for oxygenated fuels at maximum load

Figure 13 shows the cylinder pressure traces with respect to the crank position for diesel and oxygenated fuel with and without EGR. From the figure it is observed that EGR engines have a longer delay period compared to normal engines and hence the maximum pressure is reduced. The reduction in maximum cylinder pressure due to EGR for different fuels is indicated in Figure 14.

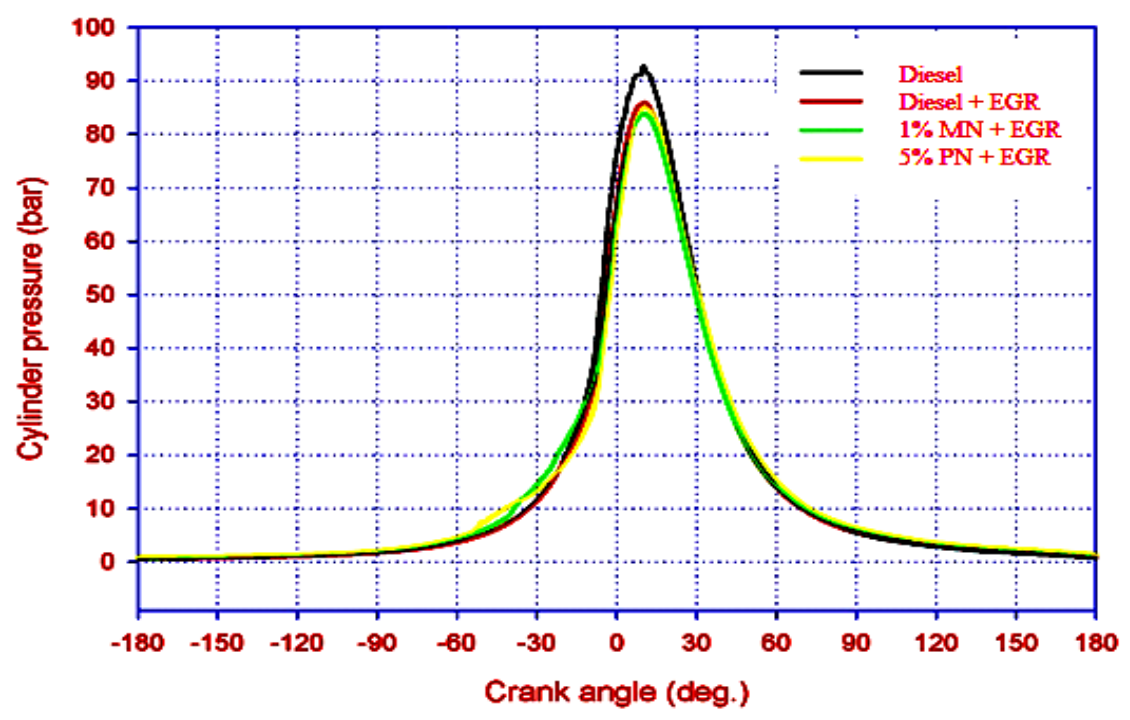

Figure 13. Variation in cylinder pressure with crank angle 


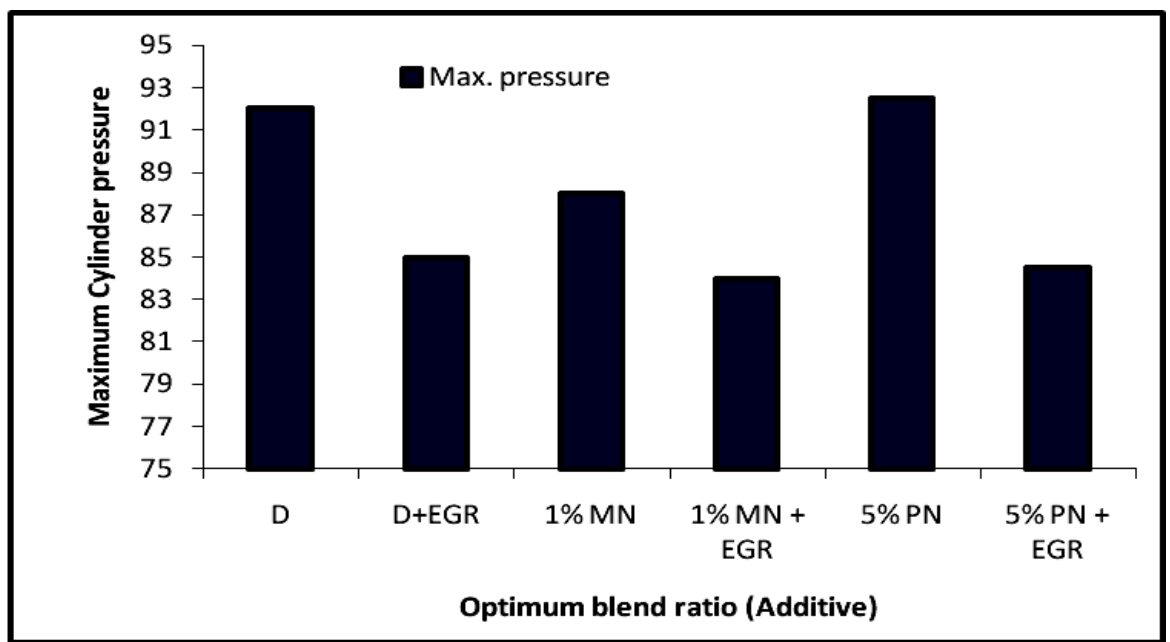

Figure 14. Effect of EGR on maximum cylinder pressure at maximum load for optimum blend fuels

Figure 15 illustrates the heat release rate for oxygenated fuel blends and unaltered fuel at maximum loading conditions. It can be seen that the heat release rate of the oxygenated fuel blends are higher than the unaltered fuel and its magnitude depends on the availability of oxygen. The higher heat release rate in diffusion combustion of the oxygenated fuel increase the net heat release rate, consequently oxygenated fuel has controlled rate of pre-mixed combustion.

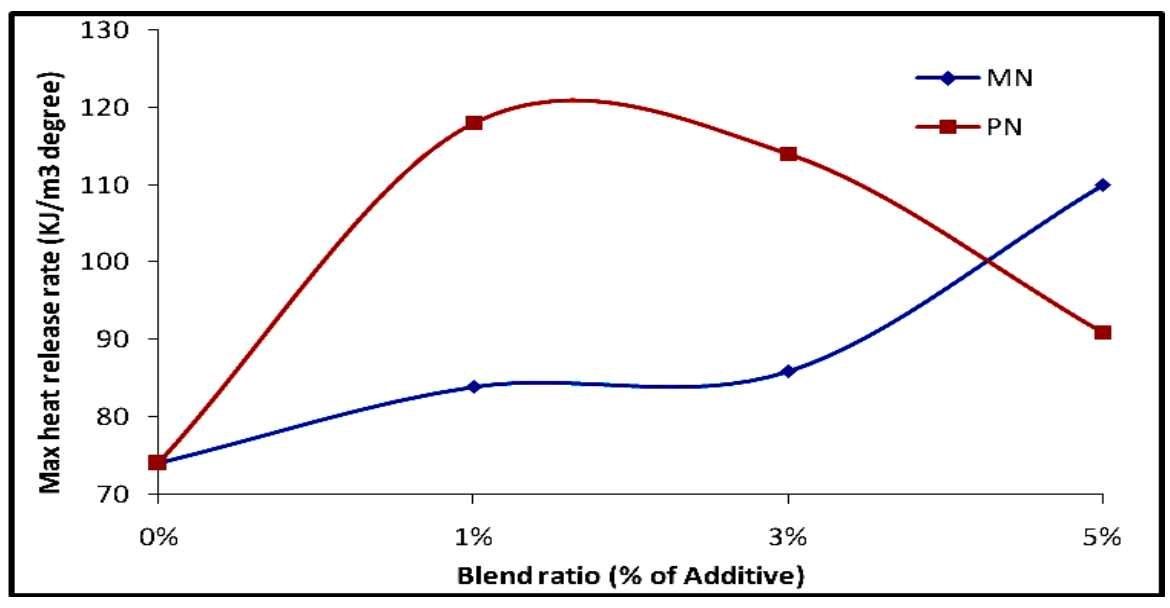

Figure 15. Variation in heat release rate for oxygenated fuels at maximum load

Figure 16 depicts the effect of EGR on the heat release rate at maximum loading conditions. EGR reduces the heat release rate substantially. The effect of EGR on heat release rate may be due to dilution caused by increasing amounts of inert gases in the mixture, which reduces the adiabatic flame temperature. 


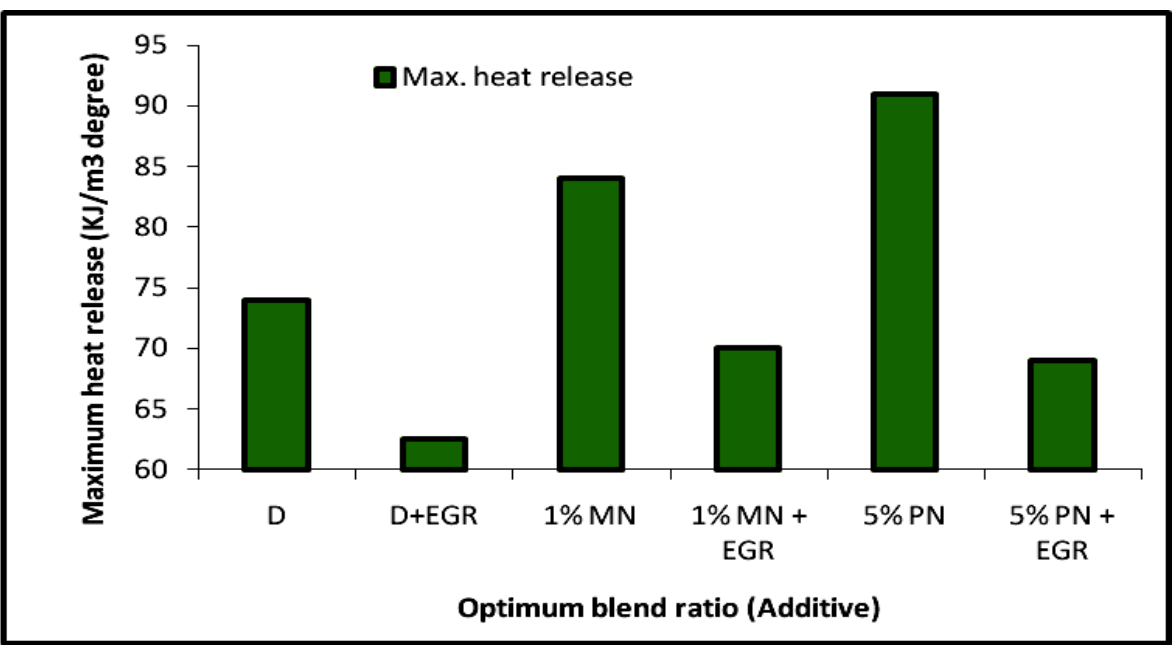

Figure 16. Effect of EGR on maximum heat release rate at maximum load

\section{CONCLUSION}

The main conclusions of this study are,

- $1 \% \mathrm{MN}$ and 5\% PN blends are the optimum in performance and emission characteristics.

- Smoke and HC reduction rate is higher for PN than MN.

- Around $20 \%$ increase in NOx emissions were observed for the oxygenated fuel blends at normal operating conditions of the engine at peak load.

- EGR reduces NOx emissions of the oxygenated fuels over 55\% since it reduces the maximum cylinder pressure and heat release rate.

- No adverse effect on efficiency and fuel economy due to EGR.

- Simultaneous reduction in NOx and smoke can be achieved by the oxygenated fuel with EGR.

On the whole it is concluded that $1 \% \mathrm{MN}$ and 5\% PN proved to be suitable oxygenated additives for diesel engines and 5\% PN with 25\% EGR can perform better than an $\mathrm{MN}$ additive with less emissions.

\section{ACKNOWLEDGEMENTS}

The authors wish to express their appreciation to Dr. C. G. Saravanan, Professor of Mechanical Engineering, Annamalai University, for his valuable suggestions

\section{REFERENCES}

Bailey, B., Goguen, J.E.S. and Erwin, J. (1997) DEE as a Renewable Diesel Fuel. SAE Paper, No. 972972.

Bennethum, J.E. and Winsor, R.E. 1991. Toward Improved Diesel Fuel. SAE Paper, No. 912325.

Brook, D,L., Rallis, C.J., Lane, N.W. and Cipolat, D. 1984. Methanol With Dimethyl Ether Ignition Promoter as a Fuel for Compression Ignition Engines. Proceedings of the 19th Intersociety Energy Conversion Conference, 2: 684. 
Dederichs, C.H. and Münchow Modern, F. (2002) Piston Ring Coatings and Liner Technology for EGR Applications, SAE Paper, No. 2002-01-0489.

Dürnholz, M., Eifler, G. and Endres, H. (1992) Exhaust-gas Recirculation-A measure to Reduce Exhaust Emissions of DI Diesel Engines. SAE Paper, No. 920725

Ecklund, E.E., Bechtold, R.L., Timbario, T.J. and McCallum, P.W. (1984) State-of-theart Report on the Use of Alcohols in Diesel Engines. SAE Paper, No. 840118.

Husberg, T., Savo Gjirja, S., Denbratt, I. and Engström, J. (2004) Visualization of EGR Influence on Diesel Combustion With Long Ignition Delay in a Heavy-Duty Engine. SAE Paper, No. 2004-01-2947.

Kouremenos, D.A., Hountalas, D.T., Binder, K.B., Raab, A. and Schnabel, M.H. (2001) Using Advanced Injection Timing and EGR to Improve DI Diesel Engine Efficiency at Acceptable NO and Soot Levels, SAE Paper, No. 2001-01-0199.

Mohanan, P., Kapilan, N. and Reddy, R.P. (2003) Effect of Diethyl Ether on the Performance and Emission of a 4 - S DI Diesel Engine. SAE Paper, No 2003-010760 .

Raj, C.S., Arul, S., Sendilvelan, S. and Saravanan, C.G. (2009a) Effect of 1, 4 Dioxane Ethanol Diesel Blends on Diesel Engine. International Journal of Engineering Research and Industrial Applications, 2(5): 197-208.

Raj, C.S., Arul, S., Sendilvelan, S. and Saravanan, C.G. (2009b) Implementation of 1, 4Dioxane Diesel Blend Fuels in Diesel Engines. Proceedings of the XXI National Conference on IC Engine and Combustion (NCICEC-2009), pp. 103-110.

Sorenson, S.C. and Mikkelsen, S.E. 1995. Performance and Emissions of a 0.273 Litre Direct Injection Diesel Engine Fuelled With Neat Dimethyl Ether. SAE Paper, No 950964.

West, B.H., Griffith, W.L. and Compere, A.L. (1990) High-Alcohol Microemulsion Fuel Performance in a Diesel Engine. SAE Paper, No 902101.

Yanfeng, G., Shenghua, L., Hejun, G., Tiegang, H. and Longbao, Z. (2007) A New Dieseloxygenates Additive and its Effects on Engine Combustion and Emissions. Applied Thermal Engineering, 27: 202-207.

\section{NOMENCLATURE}

$\begin{array}{ll}\text { BSFC } & \text { Brake Specific Fuel Consumption } \\ \text { DEE } & \text { Di Ethyl Ether } \\ \text { DME } & \text { Di Methyl Ether } \\ \text { EGR } & \text { Exhaust Gas Recirculation } \\ \text { HC } & \text { Hydrocarbon } \\ \text { HSU } & \text { Hatridge Smoke Unit } \\ \text { MEA } & \text { Methoxyethyl Acetate } \\ \text { MN } & \text { Methyl anon } \\ \text { NOx } & \text { Oxides of Nitrogen } \\ \text { PN } & \text { Pentanon } \\ \text { PPM } & \text { Particles per Million }\end{array}$

